\title{
Positive and negative cooperativity of modularly assembled zinc fingers.
}

\author{
$\operatorname{AUTHOR}(\mathrm{S})$ : \\ Imanishi, Miki; Nakamura, Atsushi; Morisaki, \\ Tatsuya; Futaki, Shiroh
}

\section{CITATION:}

Imanishi, Miki ... [et al]. Positive and negative cooperativity of modularly assembled zinc fingers.. Biochemical and biophysical research communications 2009, 387(3): 440-443

\section{ISSUE DATE:}

2009-09-25

URL:

http://hdl.handle.net/2433/134788

\section{RIGHT:}

(C) 2009 Elsevier Inc:; This is not the published version. Please cite only the published version.; この論文は出版社版でありません。引用の際に は出版社版をご確認ご利用ください。 


\title{
Positive and negative cooperativity of modularly assembled zinc fingers
}

\author{
Miki Imanishia, ${ }^{a,{ }^{*}}$, Atsushi Nakamura ${ }^{\mathrm{a}}$, Tatsuya Morisaki ${ }^{\mathrm{a}}$, Shiroh Futaki $^{\mathrm{a}}$ \\ ${ }^{a}$ Institute for Chemical Research, Kyoto University, Uji, Kyoto 611-0011, Japan \\ ${ }^{\mathrm{b}}$ PRESTO, Japan Science and Technology Agency (JST), Kawaguchi, Saitama 332-0012, Japan
}

Running title: Context-dependent DNA binding of zinc finger modules

*To whom correspondence should be addressed. M.I.: phone, +81-774-38-3212; fax, +81-774-

32-3038; e-mail, imiki@scl.kyoto-u.ac.jp

Abbreviations: $\mathrm{ZF}$, zinc finger; $\mathrm{AD}$, transcriptional activation domain; Tris, tris(hydroxymethyl)aminomethane; bp, base pair(s) 
One simple and widespread method to create engineered zinc fingers targeting the desired DNA sequences is to modularly assemble multiple finger modules pre-selected to recognize each DNA triplet. However, it has become known that a sufficient DNA binding affinity is not always obtained. In order to create successful zinc finger proteins, it is important to understand the context-dependent contribution of each finger module to the DNA binding ability of the assembled zinc finger proteins. Here, we have created finger-deletion mutants of zinc finger proteins and examined the DNA bindings of these zinc fingers to clarify the contributions of each finger module. Our results indicate that not only a positive cooperativity but also a context-dependent reduction in the DNA binding activity can be induced by assembling zinc finger modules.

Keywords: engineered zinc finger protein, DNA binding, modular assembly 
Engineered DNA binding proteins with the desired DNA binding specificity have a significant potential to control the gene expression or manipulate genetic information by fusing with transcriptional regulation domains or catalytic domains [1; 2]. The $\mathrm{C}_{2} \mathrm{H}_{2}$-type zinc finger motif is one of the best frameworks to create new artificial DNA binding proteins for the following features [3]: 1) a zinc finger motif recognizes continuous 3- to 4-bp via key amino acid residues located on the recognition $\alpha$-helix, 2) multiple zinc finger motifs are tandemly repeated by the covalent linkage, and 3) a $\mathrm{C}_{2} \mathrm{H}_{2}$-type zinc finger domain works as a monomer. So far, artificial zinc finger motifs targeting many of the 64 possible DNA triplets have been characterized by changing the key amino acid residues on the recognition helix $[4 ; 5$; $6 ; 7 ; 8]$. By taking advantage of the second feature, artificial zinc finger proteins targeting long DNA sequences were created by tandemly connecting individual zinc finger motifs $[9 ; 10 ; 11 ; 12]$. In order to create multi-finger arrays by the modular assembly approach, convenient web-based tools are available, searching for the combinations of zinc finger modules corresponding to the target DNA sequences [13; 14]. Though some of the modularly assembled zinc finger proteins could successfully work $[10 ; 15 ; 16]$, not all multi-finger arrays showed a desirable DNA binding affinity $[17 ; 18]$. In order to more efficiently create functional zinc finger proteins, it is required to understand the relationships between the DNA binding ability of the modularly assembled multi-finger proteins and the contribution of the individual finger modules. However, little information is available about these relationships. We thought that the stepwise deletions of the finger modules would provide helpful 
information. In the present study, we created modularly assembled 6-zinc finger proteins, targeting the E-box (5'-CACGTG-3')-containing sequences as an example. Because E-box is one of the most common cis-elements, it would be useful for future genomic analyses if an artificial zinc finger protein could bind to a specific E-box versus the other E-boxes. After examining the DNA binding specificity of the 6finger proteins, the contributions of the individual zinc fingers to the DNA binding activity were evaluated by creating component zinc fingers of the 6-finger proteins.

\section{MATERIALS AND METHODS}

Chemicals. The modification enzymes and restriction enzymes were purchased from New England Biolabs, except for AgeI that was obtained from Nippon Gene. The Taq DNA polymerase was acquired from Nippon Gene. The synthesized oligonucleotides were supplied from Invitrogen. All other chemicals were of commercial reagent grade.

Construction of expression vectors and reporter vectors. The multi-cloning sites containing the XmaI, EcoRI, and BamHI restriction sites were introduced between the SacI and XbaI sites of pCMV-ZF3-NLS-AD [12]. The NLS from the SV40 large Tantigen coding sequence was introduced between the EcoRI and BamHI sites, and the VP64 [10] (the tetrameric repeat of VP16 transcriptional activation domains) coding sequences were stepwisely introduced between the Bam HI and $\mathrm{XbaI}$ sites, resulting in pCMV-AD. The DNA fragments coding each zinc finger module [13] between the XmaI and AgeI sites and with the EcoRI site outside the AgeI site were generated by PCR using oligonucleotides as the templates. The N-terminal zinc finger, $\mathrm{ZF}(\mathrm{x})$, was introduced into the $\mathrm{XmaI}$ and $E c o$ RI of pCMV-AD, resulting in pCMV-ZF(x)-AD. By 
introducing the $X m a \mathrm{I} / E c o$ RI fragment coding $\mathrm{ZF}(\mathrm{y})$ to the AgeI/EcoRI sites of pCMV-ZF(x)-AD, pCMV-ZF(x)(y)-AD was constructed. By repeating such manipulations, all the expression vectors, $\mathrm{pCMV}-\mathrm{ZF}(\mathrm{E} 2-\mathrm{a} \sim \mathrm{j})-\mathrm{AD}$ and $\mathrm{pCMV}-\mathrm{ZF}(\mathrm{E} 3-$ $\mathrm{a} \sim \mathrm{c})-\mathrm{AD}$, were constructed. The firefly luciferase reporter vectors used here were constructed by introducing four repeated E-box containing sequences into pGL3-TA [12], resulting in pGL3/E-box. The DNA sequences were confirmed by a GeneRapid DNA sequencer (Amersham Bioscience).

Luciferase reporter assays. Ten nanograms of the expression vector, $400 \mathrm{ng}$ of the reporter vector, and $1 \mathrm{ng}$ of the control vector (pRL-TK; Promega) were transiently cotransfected into HeLa cells using the Lipofectamine 2000 (Invitrogen). The medium was changed at $5 \mathrm{~h}$ post-transfection, and the cell lysates were prepared using passive lysis buffer (Promega) at $48 \mathrm{~h}$ post-transfection. The firefly and renilla luciferase activity was measured using the dual luciferase reporter system (Promega). The luminescence was obtained by normalization to the transfection control.

Western blot assays. pCMV-6Myc-ZF-ZDs were created by fusing the $6 \times$ Myctag-coding sequence into the $\mathrm{N}$-terminus of the zinc finger region and transfected into HeLa cells for detection of the expressed transcription factors. Whole cell extracts were prepared at $48 \mathrm{~h}$ post-transfection in Laemmli buffer and separated on a polyacrylamide gel by electrophoresis with SDS-PAGE buffer ( $25 \mathrm{mM}$ Tris-HCl, 192 $\mathrm{mM}$ glycine, and $0.1 \%$ SDS). They were then transferred onto the Hybond-P polyvinylidene difluoride membrane (GE Healthcare). The membrane was then probed with the anti-c-Myc antibody (9E10, Santa Cruz) or with the anti- $\beta$-actin 
antibody (AC-15, Sigma) diluted in PBS containing 0.1\% Tween 20 and 2.5\% skin milk, followed by incubation with the second antibody (peroxidase conjugated antimouse IgG, GE Healthcare). The antigen-antibody complexes were visualized with ECL Plus Western blotting detection reagents (GE Healthcare) and captured with a LAS-3000 mini CCD imaging system (Fujifilm).

Preparations of zinc finger proteins. The XmaI/EcoRI fragments from the pCMV$\mathrm{ZF}(\mathrm{E} 2-\mathrm{a})-\mathrm{AD}$ were inserted into the $\mathrm{XmaI} / \mathrm{EcoRI}$ site of pEV-ZF3 [12]. The plasmids were transformed into the Escherichia coli strain BL21(DE3). The zinc finger proteins were overexpressed as a soluble form at $20{ }^{\circ} \mathrm{C}$ and purified as follows at $4{ }^{\circ} \mathrm{C}$. The E. coli cells were resuspended and lysed in PBS buffer. Purification was carried out by cation-exchange chromatography using a High S Cartridge (Bio Rad) followed by a Resource S column (GE Healthcare). Final purification was achieved by a gel filtration technique (Superdex 75; GE Healthcare) using TN buffer (10 mM Tris-HCl (pH 8.0), $50 \mathrm{mM} \mathrm{NaCl}, 1 \mathrm{mM}$ dithiothreitol).

Electrophoretic mobility shift assays (EMSA). The 5'-FITC-labeled oligonucleotides containing each E-box and the surrounding sequence were annealed with the complement oligonucleotides. EMSA were carried out under the following conditions. Each reaction mixture contained $10 \mathrm{mM}$ Tris- $\mathrm{HCl}(\mathrm{pH} 8.0), 50 \mathrm{mM} \mathrm{NaCl}$, $1 \mathrm{mM}$ dithiothreitol, $0.05 \%$ Nonidet P-40, $5 \%$ glycerol, $5 \mathrm{mM} \mathrm{MgCl}_{2}, 20 \mathrm{ng} / \mu \mathrm{L}$ calf thymus DNA (Sigma), 2.5 nM 5'-end-labeled DNA fragment, and $63 \mathrm{nM} \mathrm{ZF(E2-a)}$ protein. After incubation at $20{ }^{\circ} \mathrm{C}$ for $24 \mathrm{hr}$, the sample solutions were electrophoresed on an $8 \%$ nondenaturing polyacrylamide gel with Tris-borate buffer $(88 \mathrm{mM}$ Tris- $\mathrm{HCl}$ 
(pH 8.0) and $88 \mathrm{mM}$ boric acid) at room temperature. The bands were visualized using a FluorImager (GE Healthcare).

\section{RESULTS AND DISCUSSION}

Creation of 6-zinc finger proteins targeting a specific E-box

As the targets of the artificial zinc finger proteins, we selected the E-boxcontaining sequences on the mouse Periodl (mPerl) promoter involved in the regulation of the circadian clock. There are at least five E-box sequences (E1 E5) on the mPerl promoter [19], but the contribution of each E-box is unclear. It is required to create site-specific zinc finger proteins that can recognize a specific E-box for future genomic promoter analyses. In order to target a specific E-box, we paid attention to the differences in their surrounding sequences. Among the five E-boxes, the 10 bp sequences around the second and third E-box (E2 and E3) regions are completely similar to each other. It is important to create multi-zinc finger proteins that can discriminate between E2 and E3. Therefore, we preferentially constructed the multi-zinc finger proteins, $\mathrm{ZF}(\mathrm{E} 2-\mathrm{a})$ and $\mathrm{ZF}(\mathrm{E} 3-\mathrm{a})$, targeting $\mathrm{E} 2$ and $\mathrm{E} 3$, respectively. Six zinc finger modules [13] were assembled to target the 18 bp containing E2 or E3 (Figure 1A underlined).

The DNA binding specificity of $\mathrm{ZF}(\mathrm{E} 2-\mathrm{a})$ among the five E-boxes inside cells was examined by luciferase reporter assays by fusing $\mathrm{ZF}(\mathrm{E} 2-\mathrm{a})$ with the transcriptional activation domain (AD), VP64 [10] derived from the herpes simplex virus VP16 (Figure 1B). ZF(E2-a)-AD activated the reporter gene with the E2 sequence, but not the other E-box sequences in the promoter (Figure 1C). This result was also confirmed by electrophoretic mobility shift assays (EMSA) using the 
purified $\mathrm{ZF}(\mathrm{E} 2-\mathrm{a})$ protein. As shown in Figure 1D, ZF(E2-a) showed a shift band of the E2-containing DNA fragment, but not the other E-box containing DNAs. These results indicate that $\mathrm{ZF}(\mathrm{E} 2-\mathrm{a})$ specifically binds to the E2-containing DNA among all the E-box-containing DNA sequences on the mPerl promoter.

On the other hand, the $\mathrm{ZF}(\mathrm{E} 3-\mathrm{a})$-based transcription factor, whose DNA binding domain consists of six zinc finger modules to target the 18 bp containing the E3-box, showed only a slight transcriptional activity for the E3-containing reporter vector (data not shown). It was shown that the expected DNA binding ability cannot be always obtained by simple assembly of the zinc finger modules as shown in a previous report $[17 ; 18]$.

DNA binding of the component zinc fingers of $Z F(E 2-a)$ which specifically binds to the target DNA.

In order to examine the context-dependent contribution of each modularly assembled zinc finger on the DNA binding, the zinc finger modules included in $\mathrm{ZF}(\mathrm{E} 2-\mathrm{a})$ were deleted one by one, resulting in 5-, 4-, and 3-zinc finger proteins (Figure 2A). Because it was reported that the DNA binding affinity is related to the luciferase activity in cells (Figures 1C, D) [8; 20], the DNA binding ability of the component zinc finger modules of $\mathrm{ZF}(\mathrm{E} 2-\mathrm{a})$ was examined using luciferase reporter assays by expressing zinc fingers as transcription factors in HeLa cells (Figure 2A). All the 3-finger transcription factors, $Z F(E 2-g \sim j)-A D s$, showed almost no transcriptional activity and the others with more than four zinc fingers, except for 
$\mathrm{ZF}(\mathrm{E} 2-\mathrm{f})-\mathrm{AD}$, showed higher transcriptional activities. The transcription factors with the zinc finger module for 5'-AGT-3' at their C-terminus, namely, the 6-finger ZF(E2-a), 5-finger ZF(E2-b), and 4-finger ZF(E2-d), showed higher luciferase activities than the 5-finger $\mathrm{ZF}(\mathrm{E} 2-\mathrm{c})$, 4-finger $\mathrm{ZF}(\mathrm{E} 2-\mathrm{e})$, and 3-finger $\mathrm{ZF}(\mathrm{E} 2-\mathrm{h})$, respectively. The transcription factors with the zinc finger module for 5'-GAT-3' at their C-terminus, namely, the 5-finger $\mathrm{ZF}(\mathrm{E} 2-\mathrm{c})$ and 4-finger $\mathrm{ZF}(\mathrm{E} 2-\mathrm{e})$, showed higher luciferase activities than the 4-finger $\mathrm{ZF}(\mathrm{E} 2-\mathrm{f})$ and 3-finger $\mathrm{ZF}(\mathrm{E} 2-\mathrm{i})$, respectively. These results indicate that the zinc finger modules for 5'-AGT-3' and for 5'-GAT-3' contribute to increasing the DNA binding affinity of the modularly assembled zinc finger proteins in these contexts. Similarly, positive contributions to the DNA binding are demonstrated in the case of the zinc finger modules for 5'-GCC3' and for 5'-ACG-3'. On the other hand, the zinc finger-type transcription factors with the zinc finger module for 5'-TGA-3' at the N-terminus, namely, the 6-finger ZF(E2-a), 5-finger ZF(E2-c), and 4-finger ZF(E2-f), showed lower or almost the same activities as the 5-finger $\mathrm{ZF}(\mathrm{E} 2-\mathrm{b})$, 4-finger $\mathrm{ZF}(\mathrm{E} 2-\mathrm{e})$, and 3-finger $\mathrm{ZF}(\mathrm{E} 2-\mathrm{i})$, respectively, indicating few contributions of the N-terminus module for 5'-TGA-3' to the DNA binding of the modular zinc finger protein in these contexts. These results indicate that most of the zinc finger modules of $\mathrm{ZF}(\mathrm{E} 2-\mathrm{a})$, but the $\mathrm{N}$-terminal one for 5'-TGA-3', contributes to increasing the DNA binding affinity. Regardless of the transcriptional activities, the expression levels of all the constructs were comparable by the western blot analysis (Figure 2B). Though the 6Myc-epitope tag-fused constructs were used for detection of the expressed transcription factors, we 
confirmed that their relative transcriptional activities were similar to those without the tag.

DNA binding of the component zinc fingers of $Z F(E 3-a)$ which does not bind to the target DNA.

We next created finger-deletion mutants of the 6-zinc finger $\mathrm{ZF}(\mathrm{E} 3-\mathrm{a})$ which seems to hardly bind to the target DNA based on the luciferase assay. Their DNA binding ability was evaluated using luciferase reporter assays (Figure 3A) as well as $\mathrm{ZF}(\mathrm{E} 2-\mathrm{a} \sim \mathrm{j})$. The expression of the zinc finger-type transcription factors, 6Myc$\mathrm{ZF}(\mathrm{E} 3-\mathrm{a} \sim \mathrm{c})-\mathrm{ADs}$, was confirmed by the western blot analysis (Figure 3B). Interestingly, the 4-finger $\mathrm{ZF}(\mathrm{E} 3-\mathrm{b})-\mathrm{AD}$ showed an obvious increase in the transcriptional activity as compared to the 6-finger $\mathrm{ZF}(\mathrm{E} 3-\mathrm{a})-\mathrm{AD}$. In addition, by deleting a zinc finger module for 5'-GAC-3' from the 4-finger $\mathrm{ZF}(\mathrm{E} 3-\mathrm{b})$, the 3-fingertype transcription factor, $\mathrm{ZF}(\mathrm{E} 3-\mathrm{c})-\mathrm{AD}$, showed a much higher transcriptional activity (Figure 3A). In a previous report, the zinc finger module for 5'-GAC-3', with the same amino acid sequences we used in this study, was assembled into several 3-zinc finger proteins and they showed a DNA binding ability to the expected target sites independent of the examined neighboring zinc finger modules [18; 21]. In addition, an additive DNA binding affinity is expected from the recently reported affinity-based scoring scheme [18] by an assembly of the zinc finger module for 5'-GAC-3'. The observed decrease in DNA binding suggests that a context-dependent reduction in the 
DNA binding occurred by assembly of the zinc finger module for 5'-GAC-3', though the finger itself has the potential to recognize the triplet $[21 ; 22]$.

In this study, positive effects on the DNA binding depending on the number of finger modules were observed in the case of the 3 5-fingers of the E2-targeting zinc fingers. In such cases, all the modularly assembled fingers seem to participate in the sequence specific DNA binding. The fact that $\mathrm{ZF}(\mathrm{E} 2-\mathrm{a})$ can discriminate similar sequences containing the same cis-element sequences indicates that the modularly assembled zinc finger is a promising tool for promoter analyses. On the contrary, reduced DNA binding affinity by the addition of finger modules was also shown in the case of the 3,4, and 6-fingers of the E3-targeting zinc fingers. This contextdependent reduction in DNA binding may be explained as an event similar to that the 6-zinc finger proteins consisting of two tandemly connected 3-finger domains have a much lower affinity to the half-binding sites (9 bp) than each 3-zinc finger [10] probably because of the inadequate finger orientations. A longer linker between the zinc finger modules might overcome this problem [23]. It might also be more effective to combine the zinc finger modules with different backbones and select continuous zinc finger modules than the simple modular assembly [16; 24; 25]. So far, context-dependent effects were exemplified by the optimized zinc finger domains via a phage display [26] or by various pairs of zinc finger nucleases [16]. This is the first example to show context-dependent positive and negative effects using component zinc fingers of the 6-zinc finger proteins. Piling up information on the DNA binding 
of each component zinc finger (e.g., ZiFDB database [27]) would help to understand the DNA binding modes of the modularly assembled zinc fingers and to determine general rules for creating effective zinc fingers by modular assembly.

\section{ACKNOWLEDGEMENTS}

This work was partially supported by a Grant-in-Aid for Scientific Research from the Ministry of Education, Culture, Sports, Science and Technology, Japan and Takeda

Science Foundation to M. I.. A. N. and T. M. are research fellows of the Japan

Society for the Promotion of Science. 


\section{REFERENCES}

[1] A.C. Jamieson, J.C. Miller, C.O. Pabo, Drug discovery with engineered zinc-finger proteins, Nat. Rev. Drug Discov. 2 (2003) 361-368.

[2] P. Blancafort, D.J. Segal, C.F. Barbas, 3rd, Designing transcription factor architectures for drug discovery, Mol. Pharmacol. 66 (2004) 1361-1371.

[3] N.P. Pavletich, C.O. Pabo, Zinc finger-DNA recognition: crystal structure of a Zif268-DNA complex at 2.1 A, Science 252 (1991) 809-817.

[4] B. Dreier, D.J. Segal, C.F. Barbas, 3rd, Insights into the molecular recognition of the 5'GNN-3' family of DNA sequences by zinc finger domains, J. Mol. Biol. 303 (2000) 489502.

[5] B. Dreier, R.R. Beerli, D.J. Segal, J.D. Flippin, C.F. Barbas, 3rd, Development of zinc finger domains for recognition of the 5'-ANN-3' family of DNA sequences and their use in the construction of artificial transcription factors, J. Biol. Chem. 276 (2001) 29466-29478.

[6] T. Sera, C. Uranga, Rational design of artificial zinc-finger proteins using a nondegenerate recognition code table, Biochemistry 41 (2002) 7074-7081.

[7] B. Dreier, R.P. Fuller, D.J. Segal, C.V. Lund, P. Blancafort, A. Huber, B. Koksch, C.F. Barbas, 3rd, Development of zinc finger domains for recognition of the 5'-CNN-3' family DNA sequences and their use in the construction of artificial transcription factors, J. Biol. Chem. 280 (2005) 35588-35597.

[8] L. Zhang, S.K. Spratt, Q. Liu, B. Johnstone, H. Qi, E.E. Raschke, A.C. Jamieson, E.J. Rebar, A.P. Wolffe, C.C. Case, Synthetic zinc finger transcription factor action at an endogenous 
chromosomal site. Activation of the human erythropoietin gene, J. Biol. Chem. 275 (2000) 33850-33860.

[9] Q. Liu, D.J. Segal, J.B. Ghiara, C.F. Barbas, 3rd, Design of polydactyl zinc-finger proteins for unique addressing within complex genomes, Proc. Natl. Acad. Sci. USA 94 (1997) $5525-5530$.

[10] R.R. Beerli, D.J. Segal, B. Dreier, C.F. Barbas, 3rd, Toward controlling gene expression at will: specific regulation of the erbB-2/HER-2 promoter by using polydactyl zinc finger proteins constructed from modular building blocks, Proc. Natl. Acad. Sci. USA 95 (1998) 14628-14633.

[11] T. Kamiuchi, E. Abe, M. Imanishi, T. Kaji, M. Nagaoka, Y. Sugiura, Artificial nine zincfinger peptide with 30 base pair binding sites, Biochemistry 37 (1998) 13827-13834.

[12] T. Morisaki, M. Imanishi, S. Futaki, Y. Sugiura, Rapid transcriptional activity in vivo and slow DNA binding in vitro by an artificial multi-zinc finger protein, Biochemistry 47 (2008) 10171-10177.

[13] J.G. Mandell, C.F. Barbas, 3rd, Zinc Finger Tools: custom DNA-binding domains for transcription factors and nucleases, Nucleic Acids Res. 34 (2006) W516-523.

[14] J.D. Sander, P. Zaback, J.K. Joung, D.F. Voytas, D. Dobbs, Zinc Finger Targeter (ZiFiT): an engineered zinc finger/target site design tool, Nucleic Acids Res. 35 (2007) W599-605.

[15] R.R. Beerli, C.F. Barbas, 3rd, Engineering polydactyl zinc-finger transcription factors, Nat. Biotechnol. 20 (2002) 135-141. 
[16] H.J. Kim, H.J. Lee, H. Kim, S.W. Cho, J.S. Kim, Targeted genome editing in human cells with zinc finger nucleases constructed via modular assembly, Genome Res. (2009).

[17] C.L. Ramirez, J.E. Foley, D.A. Wright, F. Muller-Lerch, S.H. Rahman, T.I. Cornu, R.J. Winfrey, J.D. Sander, F. Fu, J.A. Townsend, T. Cathomen, D.F. Voytas, J.K. Joung, Unexpected failure rates for modular assembly of engineered zinc fingers, Nat. Methods 5 (2008) 374-375.

[18] J.D. Sander, P. Zaback, J.K. Joung, D.F. Voytas, D. Dobbs, An affinity-based scoring scheme for predicting DNA-binding activities of modularly assembled zinc-finger proteins, Nucleic Acids Res. 37 (2009) 506-515.

[19] A. Hida, N. Koike, M. Hirose, M. Hattori, Y. Sakaki, H. Tei, The human and mouse Period1 genes: five well-conserved E-boxes additively contribute to the enhancement of mPer1 transcription, Genomics 65 (2000) 224-233.

[20] J.S. Kang, Correlation between functional and binding activities of designer zinc-finger proteins, Biochem. J. 403 (2007) 177-182.

[21] D.J. Segal, R.R. Beerli, P. Blancafort, B. Dreier, K. Effertz, A. Huber, B. Koksch, C.V. Lund, L. Magnenat, D. Valente, C.F. Barbas, 3rd, Evaluation of a modular strategy for the construction of novel polydactyl zinc finger DNA-binding proteins, Biochemistry 42 (2003) 2137-2148.

[22] D.J. Segal, B. Dreier, R.R. Beerli, C.F. Barbas, 3rd, Toward controlling gene expression at will: selection and design of zinc finger domains recognizing each of the 5'-GNN-3' DNA target sequences, Proc. Natl. Acad. Sci. USA 96 (1999) 2758-2763. 
[23] J.S. Kim, C.O. Pabo, Getting a handhold on DNA: design of poly-zinc finger proteins with femtomolar dissociation constants, Proc. Natl. Acad. Sci. USA 95 (1998) 2812-2817.

[24] M. Isalan, A. Klug, Y. Choo, A rapid, generally applicable method to engineer zinc fingers illustrated by targeting the HIV-1 promoter, Nat. Biotechnol. 19 (2001) 656-660.

[25] M.L. Maeder, S. Thibodeau-Beganny, A. Osiak, D.A. Wright, R.M. Anthony, M. Eichtinger, T. Jiang, J.E. Foley, R.J. Winfrey, J.A. Townsend, E. Unger-Wallace, J.D. Sander, F. Muller-Lerch, F. Fu, J. Pearlberg, C. Gobel, J.P. Dassie, S.M. Pruett-Miller, M.H. Porteus, D.C. Sgroi, A.J. Iafrate, D. Dobbs, P.B. McCray, Jr., T. Cathomen, D.F. Voytas, J.K. Joung, Rapid "open-source" engineering of customized zinc-finger nucleases for highly efficient gene modification, Mol. Cell 31 (2008) 294-301.

[26] S.A. Wolfe, H.A. Greisman, E.I. Ramm, C.O. Pabo, Analysis of zinc fingers optimized via phage display: evaluating the utility of a recognition code, J. Mol. Biol. 285 (1999) 19171934.

[27] F. Fu, J.D. Sander, M. Maeder, S. Thibodeau-Beganny, J.K. Joung, D. Dobbs, L. Miller, D.F. Voytas, Zinc Finger Database (ZiFDB): a repository for information on $\mathrm{C} 2 \mathrm{H} 2$ zinc fingers and engineered zinc-finger arrays, Nucleic Acids Res. 37 (2009) D279-283. 


\section{FIGURE LEGENDS}

\section{Figure 1}

ZF(E2-a) selectively recognizes the second E box-containing DNA. (A) The second and third Eboxes and their surrounding DNA sequences in the mPerl promoter. The square shows the Ebox sequences. The identical bases are indicated with asterisks. 6-zinc finger proteins, ZF(E2-a) and $\mathrm{ZF}(\mathrm{E} 3-\mathrm{a})$, were designed targeting the underlined sequences. (B) Schematic representation of the expression vector and the reporter vector used for luciferase reporter assays. The E-box sequence varies from the first to fifth E-box-containing sequences. (C) Luciferase activity by expression of $\mathrm{ZF}(\mathrm{E} 2-\mathrm{a})-\mathrm{AD}$ from each reporter is represented as a relative value to that obtained with the mock-expression vector. Each value is mean \pm SD. (D) Electrophoretic mobility shift assay for DNA binding of purified ZF(E2-a) protein to E1, E2, E3, E4, and E5 -containing DNA.

\section{Figure 2}

Finger deletion results in decrease in the luciferase activities of artificial zinc finger-type transcription factors targeting the second E-box-containing sequence. (A) (left) The DNA sequence represents the target site of $\mathrm{ZF}(\mathrm{E} 2-\mathrm{a})$. Each square represents a zinc finger motif expected to recognize the above DNA triplets. Multiple zinc fingers are tandemly connected as shown. The right and left squares correspond to the $\mathrm{N}$ - and $\mathrm{C}$-terminal fingers, respectively. (right) Luciferase activity by expression of each $\mathrm{ZF}(\mathrm{E} 2-\mathrm{a} \sim \mathrm{j})-\mathrm{ADs}$ is represented as a relative percentage to the maximum activity obtained by expression of $\mathrm{ZF}(\mathrm{E} 2-\mathrm{b})-\mathrm{AD}$. Each value is mean \pm SD. The significance levels were judged vs. ZF(E2-b)-AD unless the comparison subjects are 
indicated $\left({ }^{* *} \mathrm{p}<0.01\right.$, n.s., not significant). (B) Western blot analysis using anti Myc-tag antibody.

Figure 3.

Finger deletion results in increase in the luciferase activities of artificial zinc finger-type transcription factors targeting the third E-box-containing sequence. (A) (left) The DNA sequence represents the target site of $\mathrm{ZF}(\mathrm{E} 3-\mathrm{a})$. Each square represents a zinc finger motif expected to recognize the above DNA triplets. Multiple zinc fingers are tandemly connected as shown. (right) Luciferase activity by expression of each $\mathrm{ZF}(\mathrm{E} 3-\mathrm{a} \sim \mathrm{c})-\mathrm{ADs}$ is represented as a relative percentage to the maximum activity obtained by expression of $\mathrm{ZF}(\mathrm{E} 3-\mathrm{c})-\mathrm{AD}$. Each value is mean \pm SD. ${ }^{*} \mathrm{p}<0.05$ and ${ }^{* *} \mathrm{p}<0.01$. (B) Western blot analysis using anti Myc-tag antibody. 
A

E2: 5' - TAgtgatagag CACGTGagGGGGGGGC -3'

E3: 5' - GAAAGCTtTAgqCACGtGACAGTGAGGG -3'

B

Expression vector

\section{$Z F(E 2-a)-N L S-4 x V P 16$}

Reporter vector
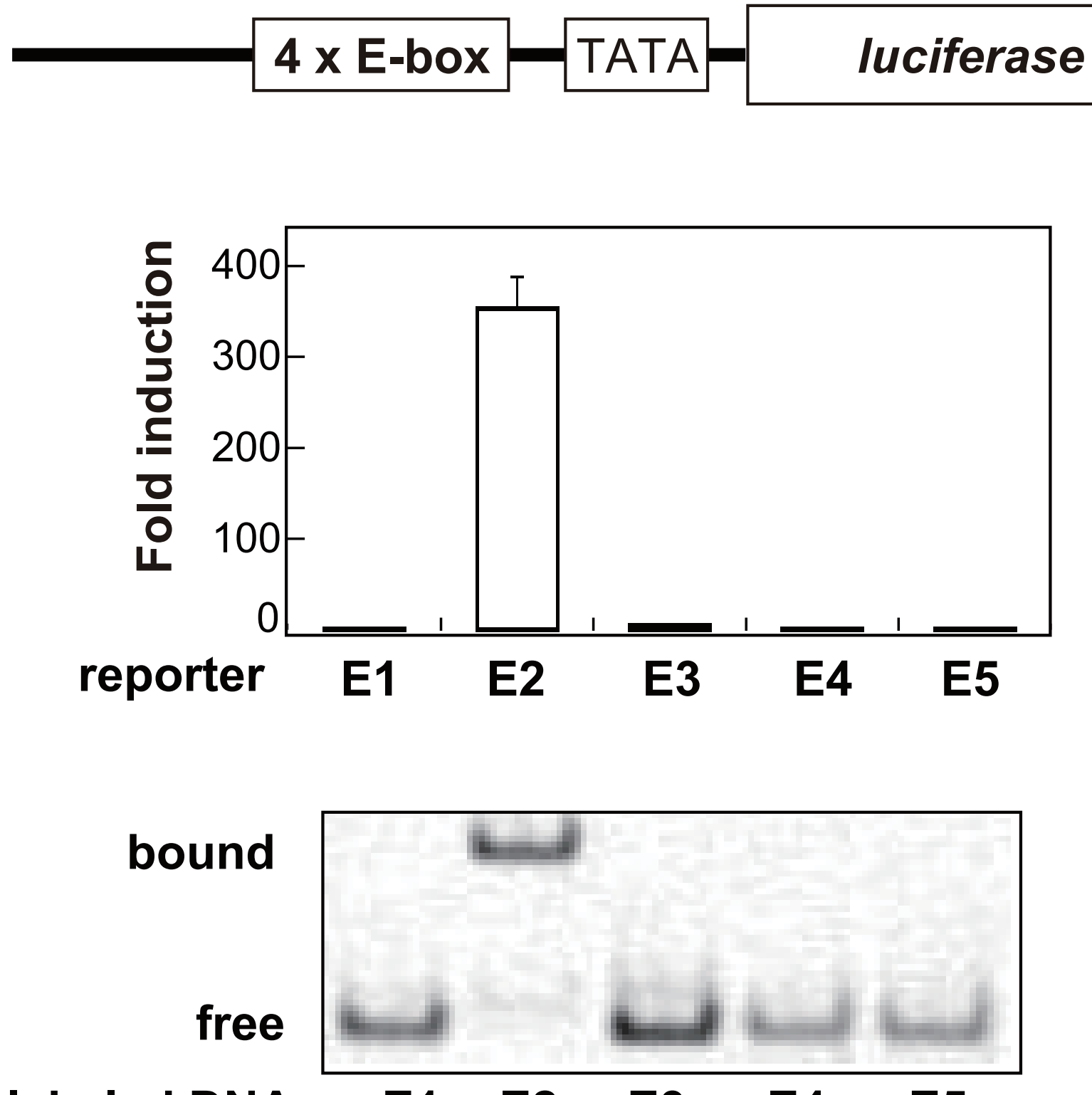

$\begin{array}{llllll}\text { labeled DNA } & \text { E1 } & \text { E2 } & \text { E3 } & \text { E4 } & \text { E5 }\end{array}$ 


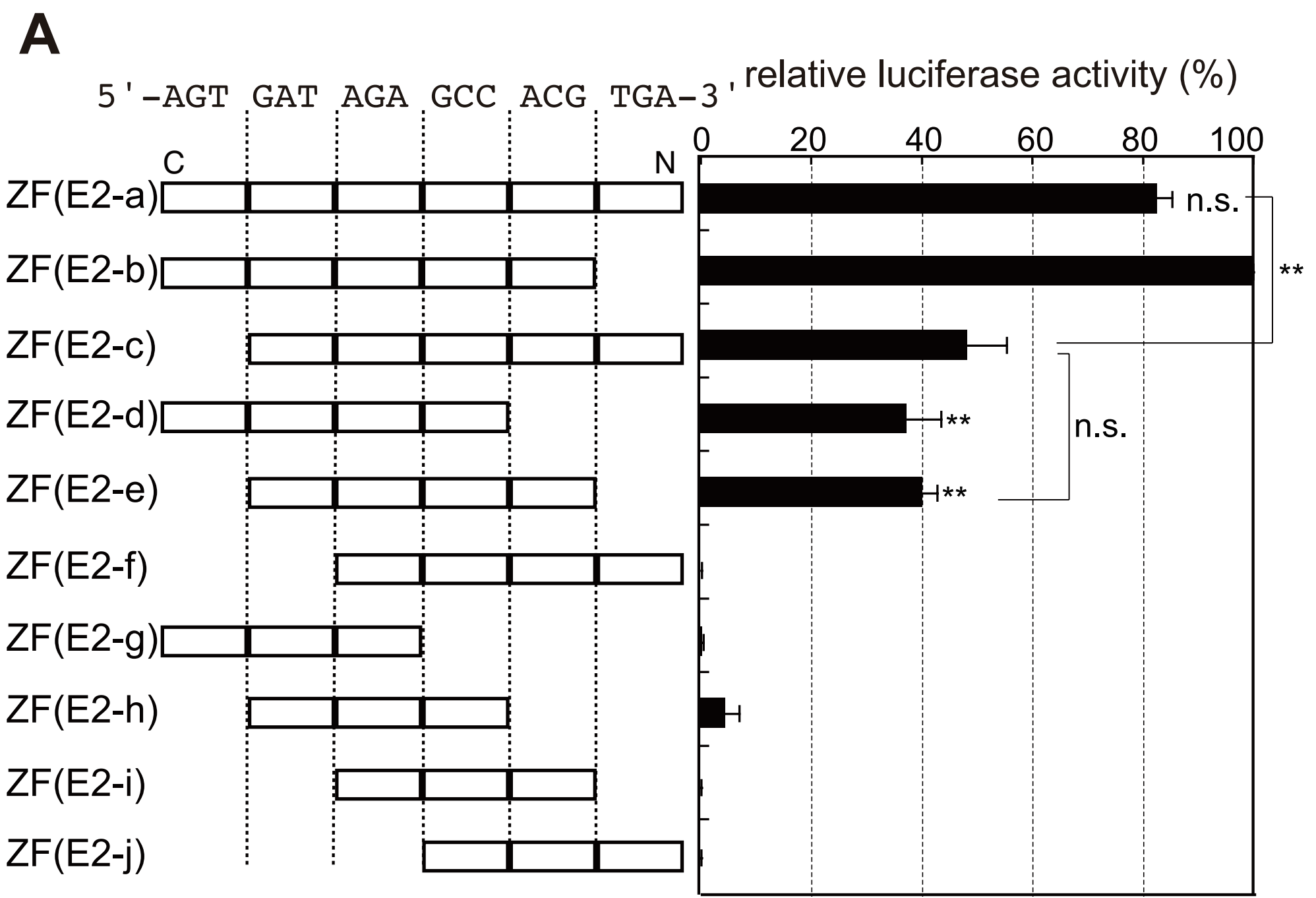

B

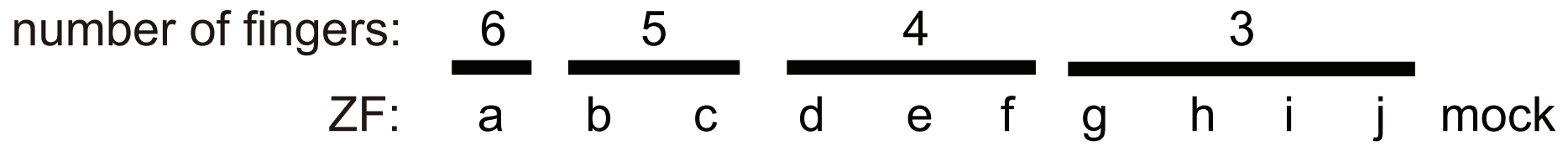

WB: anti Myc-tag

WB: anti $\beta$-actin 


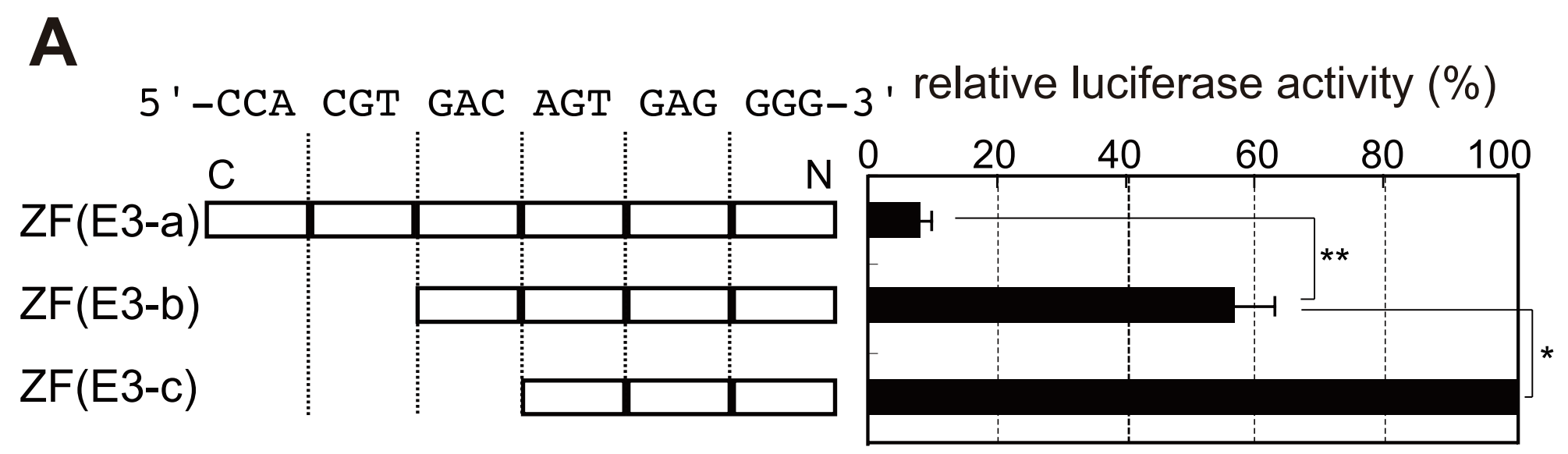

B

number of fingers:

ZF: mock $\frac{6}{a} \frac{4}{c}$

WB: anti Myc-tag

WB: anti $\beta$-actin

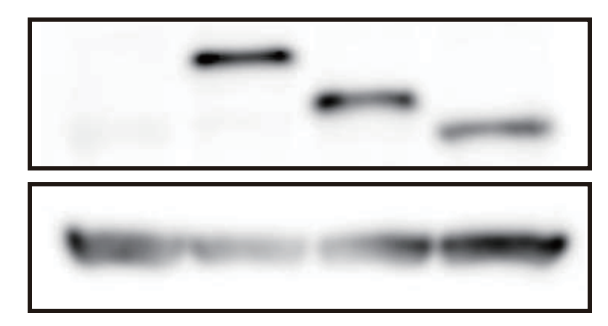

